\title{
Are aluminium potroom workers at increased risk of neurological disorders?
} Malcolm Sim, Robert Dick, John Russo, Bruce Bernard, Paula Grubb, Edward Krieg Jr,
Charles Mueller, Charles McCammon

\begin{abstract}
Objective-To determine whether long term potroom workers in an aluminium smelter are at increased risk of neurological disorders.

Methods-Cross sectional study of $63 \mathrm{cur}$ rent and former aluminium potroom workers first employed before 1970 and with at least 10 years of service. A group of 37 cast house and carbon plant workers with similar durations of employment and starting dates in the same smelter were used as controls. The prevalence of neurological symptoms was ascertained by questionnaire. Objective tests of tremor in both upper and lower limbs, postural stability, reaction time, and vocabulary were conducted. All subjects were examined by a neurologist.
\end{abstract}

Results-No significant differences in age, race, or education were found between the two groups. Although the potroom group had higher prevalences for all but one of the neurological symptoms, only three odds ratios (ORs) were significantly increased; for incoordination (OR 10.6), difficulty buttoning (OR 6.2), and depression $(O R$ 6.2). Tests of arm or hand and leg tremor in both the visible and non-visible frequencies did not show any significant differences between the two groups. Testing of postural stability showed no definitive pattern of neurologically meaningful differences between the groups. There were no significant differences between the two groups in reaction time, vocabulary score, or clinical neurological assessment.

Conclusions-The objective measures of neurological function provided little support for the finding of increased neurological symptom prevalences in the potroom workers, although increased symptoms may be an indicator of early, subtle neurological changes. The results provide no firm basis for concluding that neurological effects among long term potroom workers are related to the working environment, in particular aluminium exposure, in potrooms. These findings should be treated with caution due to the low participation of former workers and the possibility of information bias in the potroom group.
Keywords: aluminium smelting; neurological function; tremor; incoordination

A possible link between work with aluminium and neurological disorders was first raised in a published report in 1962, documenting the case of a worker exposed to aluminium who developed pulmonary fibrosis, rapidly progressive encephalopathy, and seizures. ${ }^{1}$ Two subsequent case series reports have provided some support for this link. Three aluminium potroom workers who worked at the same plant presented with incoordination, intention tremor, and cognitive deficits. ${ }^{2}$ This condition was labelled "potroom palsy". The authors hypothesised that the neurological deficits were most likely related to aluminium exposure in the potroom. A further case series report of 25 potroom workers from this same plant, including the three workers described in the original case series, found that the most often reported symptoms were frequent loss of balance $(88 \%)$, memory loss $(84 \%)$, joint pain (84\%), dizziness $(80 \%)$, numbness $(80 \%)$, and severe weakness $(80 \%))^{3}$

Neurological evaluation found that one or more of tremor, dyssynergy of upper limb movements, and ataxia were present in $84 \%$ of the 25 patients. In each of these case series, there was no control group for comparison.

Despite these results, there have been few published epidemiological studies investigating the neurological effects of long term occupational exposure to aluminium. One study found a $9 \%$ prevalence of pyramidal and cerebellar changes in a group of 444 aluminium electrolysis workers, but there was no unexposed group for comparison. ${ }^{4}$ The cognitive functioning of miners who were exposed to a finely ground aluminium powder, as a purported prophylaxis against silicotic lung disease, was more likely to be in the impaired range, compared with the cognitive functioning of unexposed miners. ${ }^{5}$ Impairment in the exposed group increased with duration of exposure. The finding of mildly impaired cognitive function was also reported in another study of workers inhaling aluminium dust, but this was a young group with short periods of exposure. ${ }^{6}$ A study of 65 welders found significantly more neuropsychiatric symptoms than those reported in a control group. ${ }^{7}$ However, the welders had been exposed to several metals in the welding fume, making it difficult to identify the role of aluminium.

The only published study carried out in the aluminium industry is a cross sectional study of neuropsychological deficit in recently 
retired workers in a Norwegian primary aluminium plant. ${ }^{8}$ This study found that a group of 14 potroom workers and 22 foundry workers was more likely than a control group of 16 workers to have reported three or more neuropsychiatric symptoms, evidence of subclinical tremor, and a tendency towards impaired visuospatial organisation. As the numbers in the study groups were small and the use of recent retirees may be subject to survivor bias, these results should be interpreted with caution. Also, the presence of tremor was assessed indirectly by a test for static steadiness and there was no objective test of incoordination.

In each of these studies, aluminium exposure has been suggested as the likely cause of the neuropsychological disorders. The role of aluminium in dialysis encephalopathy in patients with renal failure has been well documented, ${ }^{9}$ but the role of aluminium as a cause of Alzheimer's disease has been controversial. ${ }^{10}$ However, the primary route of absorption in an occupational setting (inhalation) is very different from the route of absorption in each of these settings; intravenously for dialysis patients and gastrointestinal for the proposed link with Alzheimer's disease. Kinetic studies of aluminium workers have shown that aluminium is absorbed into the body through inhalation and that the half life increases with the duration of exposure, ${ }^{11}$ as the aluminium is retained in at least two functional components of the body. ${ }^{12}$ It has been shown that absorbed aluminium after long term exposure is retained in the body for several years after the end of exposure. ${ }^{13}$

After the publication of the case series of the 25 patients already described, ${ }^{3}$ the United States National Institute for Occupational Safety and Health (NIOSH) received a request to further investigate neurological function in workers in the aluminium smelter where these patients had worked. The primary objectives of the study were to evaluate the presence of neurological symptoms, abnormal neurological findings on clinical examination, and measures of neurological function-in particular, tremor and incoordination-in long term former and current potroom workers exposed to aluminium. This study was designed to improve on the methodology used in previous studies by studying a larger group of workers, including a control group and incorporating objective measures of neurological function, including tests of tremor and postural sway.

\section{Methods \\ EXPOSURE}

To assist in selecting groups of workers to take part in the study, the available company occupational hygiene data was reviewed to estimate aluminium exposures in the potroom and other parts of the plant. No aluminium air monitoring had been regularly performed by the company. The smelter, established in 1966, uses the side-break, pre-bake HallHeroult process to reduce alumina into aluminium. There has been little change to the production methods or raw materials since production began. However, the pots were not enclosed until 1972, when hoods were added. Most of the personal air samples collected between 1968 and 1988 had measured total particulates, which were consistently higher in the potrooms (mean of $12.5 \mathrm{mg} / \mathrm{m}^{3}$ ) than in the carbon plant (mean of $10.5 \mathrm{mg} / \mathrm{m}^{3}$ ), which was higher than the concentrations in the cast house (mean of $4.5 \mathrm{mg} / \mathrm{m}^{3}$ ). A NIOSH survey in the potrooms in 1973, after the hoods were fitted, found that air concentrations of total particulate were three to eight times greater in the non-hooded pot areas than in the hooded pot areas, indicating far greater worker exposure in the potrooms before hoods were installed. ${ }^{14}$

Air samples collected in 1988, which documented the amount of respirable aluminium exposure by department, together with the mean particulate concentrations between 1968 and 1988, were used to estimate likely average exposures to respirable aluminium. The 1988 samples showed that the carbon plant had 1.9 times more exposure to respirable aluminium dust than the cast house, and the potrooms had 6.3 times more aluminium exposure than the cast house. In these samples, $19 \%-34 \%$ of the total particulate was respirable, and of the respirable fraction, $70 \%-94 \%$ was aluminium. The calculated crude estimates indicated that potroom workers were exposed to higher concentrations of respirable aluminium particulate (estimated mean $0.5 \mathrm{mg} / \mathrm{m}^{3}$ ) than workers in either the carbon plant (estimated mean $0.15 \mathrm{mg} / \mathrm{m}^{3}$ ) or the cast house (estimated mean $0.08 \mathrm{mg} / \mathrm{m}^{3}$ ). All were below the American Conference of Governmental Industrial Hygienists (ACGIH) threshold limit value of $10 \mathrm{mg} / \mathrm{m}^{3}$.

\section{STUDY GROUPS}

The exposure data outlined above was used to help define criteria for the two groups to be included in the study. These groups were selected to maximise differences in aluminium exposure with the following criteria: the potroom group comprised all workers who had worked for at least two years in the potroom before 1 January 1972 - that is, before ventilation hoods were placed on pots-and had at least 10 years of work in the potroom. The control group comprised all workers who had worked for at least two years in the cast house or carbon plant before 1 January 1972, had at least 10 years of work in the cast house or carbon plant, and no periods of work in the potroom. Work history data were extracted from personnel records to identify eligible workers in each group. In total, 98 potroom workers (65 still employed and 33 former workers) and 76 control workers (49 still employed and 27 former workers) met the eligibility criteria. All were invited to take part in the study. Before the study the protocol was approved by the NIOSH human subjects review board.

\section{DATA COLLECTION}

The study was cross sectional in design and data collection was conducted on site at the 
plant over a six day period in November 1993. Current workers from each group were randomly taken off the production line to be tested over a 90 minute period. Former workers were brought in from outside the plant for testing. All subjects gave written, informed consent. Although the testing was done on site, it was not easy to identify subjects from different parts of the plant, and this assisted in blinding the examiners to the exposure status of each participant. Also, subjects were asked not to discuss their work area with examiners. After neurological testing and undergoing standardised neurological examination by a neurologist, subjects were asked to complete a self administered questionnaire, containing questions about demographic factors, medical history, neurological symptoms, and potential confounders, such as alcohol intake and cigarette smoking.

Hand or arm tremor was measured with a hand held device that uses accelerometers mounted inside a $\mathrm{T}$ shaped apparatus made of plastic pipe to measure dynamic aspects of the amplitude and frequency of hand movements. ${ }^{15}$ Tremor in both the horizontal and vertical directions was measured and characterised over a three minute period. Leg tremor was assessed by an inductive field method with a modified test device that measured the amplitude and frequency of leg or foot movements. ${ }^{16}$ Participants extended their preferred leg into an open picture frame type device which measured tremor by displacement during a three minute period.

The postural stability test was conducted with a strain gauge force platform. ${ }^{17}$ The platform senses the participant's centre of mass 10 times a second over the 30 second time span of each test. Software developed by the manufacturer converts the 300 recorded centre of mass positions into measures of the overall path length, path area, and mean radius of the polygon created by tracing the moving centre of mass. Each participant was tested in each of the following six conditions: standing on both feet with eyes open, standing on both feet with eyes closed, standing on a four inch deep compliant foam pad with eyes open, standing on the foam pad with eyes closed, standing on the left leg with eyes open, and standing on the right leg with eyes open. With less stable test conditions - such as eyes closed, one leg, or an unstable surface-the sensitivity of the test increased as there is a greater degree of background postural instability under these conditions.

Reaction time, a test of visuomotor speed and processing, was assessed with a testing device comprising a console with a small indicator light and push button. This device is a

Table 1 Demographic characteristics of potroom and control workers

\begin{tabular}{|c|c|c|c|c|c|}
\hline & \multirow{2}{*}{$\begin{array}{l}\text { Age (y) mean } \\
(S D, \text { range })\end{array}$} & \multicolumn{2}{|c|}{ Race $(n(\%))$} & \multicolumn{2}{|c|}{ Education (n (\%)) } \\
\hline & & White & Non-white & $<12 y$ & $\geqslant 12 y$ \\
\hline $\begin{array}{l}\text { Potroom workers } \\
(\mathrm{n}=63) \\
\text { Controls }(\mathrm{n}=37)\end{array}$ & $\begin{array}{l}54 \cdot 0(6 \cdot 2,48 \cdot 3-68 \cdot 4) \\
53 \cdot 9(7 \cdot 4,43 \cdot 5-74 \cdot 9)\end{array}$ & $\begin{array}{l}57(90) \\
30(81)\end{array}$ & $\begin{array}{l}6(10) \\
7(19)\end{array}$ & $\begin{array}{r}15(24) \\
8(22)\end{array}$ & $\begin{array}{l}47(76) \\
29(78)\end{array}$ \\
\hline
\end{tabular}

component of the WHO-NIOSH neurobehavioural core test battery and is a standard component of clinical and neurobehavioural assessment. ${ }^{18}$ The procedure was repeated for 64 trials over a six minute period.

Vocabulary testing was assessed with the revised Wechsler adult intelligence scale (WAIS-Ra) vocabulary component. ${ }^{19}$ This test was used as it provides an index of verbal intelligence that is more stable over time than other measures of intelligence. Differences in intelligence can account for differences in motor function between groups and it may be necessary to adjust for this factor.

\section{STATISTICAL ANALYSIS}

The statistical analysis was conducted with the statistical analysis system (SAS) for PC, version $6 \cdot 04$. Continuous variables were analysed with Student's $t$ tests. For dichotomous categorical data, $2 \times 2$ tables were constructed and odds ratios (ORs) with $95 \%$ confidence intervals $(95 \% \mathrm{CIs})$ were calculated with exact methods. StatXact was used to estimate ORs for the symptom data as several of the cells had expected counts of less than five, and in many cases the cell counts were zero.

Summary measurements of tremor were developed by fast Fourier transformation of each sample measurement into a power spectrum of 256 discrete points covering a frequency range of $0-30 \mathrm{~Hz}$. This power spectrum provides a summary measure of amplitude of the tremor in both horizontal and vertical directions. Data reduction techniques were used to create $181 \mathrm{~Hz}$ power bands $(1-18 \mathrm{~Hz})$, which were transformed to natural logarithms for statistical analysis. Two statistical analyses were run: an analysis of group differences with repeated measures analysis of variance (ANOVA) for both power (amplitude) and frequency; and a $\chi^{2}$ analysis of the distribution of individual scores.

Because of the low participation rates for former workers in both the study and control groups, and the small number of compensation claimants, the analyses were repeated with former workers and compensation claimants excluded.

\section{Results}

Of the 65 potroom workers still employed in the plant who met the eligibility criteria, 52 took part in the study ( $80 \%)$. Of the 33 former potroom workers who met the eligibility criteria, 11 took part $(33 \%)$. Of the 49 control workers still employed in the plant who met the eligibility criteria, 35 took part in the study (71\%). Of the 27 former control workers who met the eligibility criteria, two took part $(7 \%)$. A total of 100 workers (63 potroom workers and 37 controls), all of whom were men, took part in the study. Four of the potroom group had put in previous compensation claims for neurological disorders, and were members of the 25 patient case series previously published. ${ }^{3}$

Table 1 shows the demographic characteristics of the two groups. There were no signifi- 
cant differences between the potroom and control workers for age, race, or education, which was used as a surrogate of socioeconomic status. The analysis was repeated with the former workers excluded and, again, no significant differences were found for these three demographic variables. Also, there were no significant differences between the two groups for smoking or alcohol drinking.

\section{NEUROLOGICAL SYMPTOMS}

Odds ratios with $95 \%$ CIs were calculated for neurological symptoms reported on the self administered questionnaire. As the numbers were small, the four frequency categories for each symptom (not at all, a little, moderately, and quite a lot) were dichotomised by collapsing them into two categories (not at all and a little, and moderately and quite a lot) for calculation of the ORs. As several of these dichotomised symptoms yielded $2 \times 2$ tables with cell counts of zero and expected counts of less than five, StatXact was used to obtain a median unbiased estimate of the point estimates and exact $95 \%$ CIs for the ORs.

Table 2 shows the results of these analyses. For all of these symptoms, except weight loss, the point estimates for the ORs were higher for the potroom group, ranging from 1.43 for appetite loss to 10.59 for incoordination. Because of the small numbers in the groups, the CIs for these ORs were very wide, with only three achieving significance (for incoordination, depression, and difficulty buttoning clothes). When the analyses were repeated with former workers and the four compensation claimants excluded from the analysis, the ORs for depression and difficulty buttoning were lower and no longer significant.

Table 3 shows the number of symptoms reported by members of each group to find whether a subset of workers was reporting multiple symptoms. As one of the cells was

Table 2 Reported neurological symptoms by group

\begin{tabular}{lccc}
\hline & $\begin{array}{l}\text { Prevalence } \\
\text { potroom }\end{array}$ & $\begin{array}{l}\text { Prevalence } \\
\text { control group }\end{array}$ & OR (95\% CI (exact)) \\
\hline Tiring & $27 \cdot 0 \%$ & $10 \cdot 8 \%$ & $3 \cdot 05(0 \cdot 87$ to $13 \cdot 47)$ \\
Memory trouble & $30 \cdot 2 \%$ & $21 \cdot 6 \%$ & $1 \cdot 57(0 \cdot 56$ to $4 \cdot 69)$ \\
Difficulty concentrating & $19 \cdot 0 \%$ & $8 \cdot 1 \%$ & $2 \cdot 67(0.65$ to $15 \cdot 67)$ \\
Confusion & $9 \cdot 5 \%$ & $0 \%$ & $5 \cdot 15^{\star}(0 \cdot 94$ to $\infty)$ \\
Difficulty understanding & $7 \cdot 9 \%$ & $2 \cdot 7 \%$ & $3 \cdot 10(0 \cdot 33$ to $150 \cdot 8)$ \\
Incoordination & $17 \cdot 5 \%$ & $0 \%$ & $10 \cdot 59^{\star}(2 \cdot 11$ to $\infty)$ \\
Imbalance & $14 \cdot 3 \%$ & $2 \cdot 7 \%$ & $6 \cdot 00(0 \cdot 76$ to $270 \cdot 2)$ \\
Difficulty buttoning & $11 \cdot 1 \%$ & $0 \%$ & $6 \cdot 16^{\star}(1 \cdot 16$ to $\infty)$ \\
Difficulty writing & $6 \cdot 3 \%$ & $0 \%$ & $3 \cdot 23^{\star}(0 \cdot 54$ to $\infty)$ \\
Shaking & $15 \cdot 9$ & $5 \cdot 4$ & $3 \cdot 30(0 \cdot 64$ to $32 \cdot 46)$ \\
Appetite loss & $3 \cdot 2 \%$ & $0 \%$ & $1 \cdot 43^{\star}(0 \cdot 17$ to $\infty)$ \\
Depression & $11 \cdot 1 \%$ & $0 \%$ & $6 \cdot 16^{\star}(1 \cdot 16$ to $\infty)$ \\
Weight loss & $0 \%$ & $5 \cdot 4 \%$ & $0 \cdot 24(0.00$ to $2 \cdot 02)$ \\
Irritable & $9 \cdot 6 \%$ & $2 \cdot 7 \%$ & $3 \cdot 79(0.43$ to $179 \cdot 1)$ \\
Mood changes & $12 \cdot 7 \%$ & $2 \cdot 7 \%$ & $5 \cdot 24(0.65$ to $238 \cdot 7)$ \\
\hline
\end{tabular}

*StatXact calculated a median unbiased estimate of the OR when cell counts were zero.

Table 3 Number of positive symptoms reported by group*

\begin{tabular}{lllll}
\hline & $\begin{array}{l}\text { Symptoms } \\
n(\%)\end{array}$ & $\begin{array}{l}\text { Symptom } \\
n(\%)\end{array}$ & $\begin{array}{l}2-4 \\
\text { Symptoms } \\
n(\%)\end{array}$ & $\begin{array}{l}\text { Symptoms } \\
n(\%)\end{array}$ \\
\hline Potroom workers $(\mathrm{n}=63)$ & $30(48)$ & $9(14)$ & $14(22)$ & $10(16)$ \\
Controls $(\mathrm{n}=37)$ & $25(68)$ & $5(13)$ & $7(19)$ & $0(0)$ \\
\hline
\end{tabular}

$\star \mathrm{P}=0.036$ (Fisher's exact test). less than five, Fisher's exact test was used to show that the potroom group more commonly reported multiple symptoms than the control group $(P=0.036)$.

\section{NEUROLOGICAL SIGNS}

The general level of alertness was assessed by medical examination as normal for all participants in each group. The general mental state of each participant was assessed by the neurologist as follows: four (6\%) of the potroom group (and two (5\%) of the control group) were classified as tense, one (3\%) was agitated, and one (3\%) was depressed. The rest of the participants in both groups were classified as normal. On the mini mental state examination, the mean score out of 30 for the potroom group was 29.4 and for the control group it was $29 \cdot 2$.

Thirty three $(52 \%)$ of the potroom group and $15(41 \%)$ of the control group were found to have at least one neurological abnormality. The OR was 1.62 with a $95 \%$ CI of 0.71 to 3.67. Nine of the 33 people with neurological abnormalities in the potroom group were noted to have tremor, usually of the upper limb, but in one case, of the head. Five of the 15 people with neurological abnormalities in the control group were also noted to have tremor. Three of the potroom group had unsteadiness on tandem gait, whereas no workers in the control group had this abnormality. No significant differences were found between the groups for any of the neurological abnormalities examined relevant to the disorders postulated to be related to work in potrooms. There were several other abnormalities found for which non-occupational causes were present - such as diabetic neuropathy, familial ptosis, and upper extremity tremor induced by medication.

\section{TREMOR}

To test for differences between the groups, the measurements were subdivided into those that characterised visible tremor $(1-6 \mathrm{~Hz})$ and those that characterised part of the non-visible tremor range $(7-12 \mathrm{~Hz})$. No analysis was performed on the rest of the non-visible range $(13-18 \mathrm{~Hz})$ as the power in this frequency band was too low to be meaningful.

A fatigue effect was found for both visible and non-visible tremor, characterised by an increase in tremor over time, confirming the sensitivity of the tremor test. To control for the effect of the fatigue variable, the analysis comparing the groups was performed only for the measurements in minute two of the three minute test period. The subject's measurements in the second minute were less variable because they were not still correcting their target aim (which tends to occur in the first minute) and the fatigue effects were not yet present (fatigue effects tend to maximise in the third minute).

Table 4 shows the results, which indicate no significant differences between the groups on power (amplitude) or frequency for both the visible and non-visible range of arm tremor in either horizontal or vertical directions. 
Table 4 Log power values and peak frequencies for arm tremor for minute two

\begin{tabular}{lcc}
\hline & Potroom group & Control group \\
\hline Total power $(1-6 \mathrm{~Hz}):^{\star}$ & $46.84(5.38)$ & \\
$\quad$ Horizontal & $48.66(5.07)$ & $46.76(3.39)$ \\
$\quad$ Vertical & $51.92(5.57)$ & $48.19(3.32)$ \\
Total power $(7-12 \mathrm{~Hz}):^{\star}$ & $48.57(5.11)$ & $52.09(4 \cdot 68)$ \\
$\quad$ Horizontal & $3.21(1.74)$ & $49.06(3.90)$ \\
$\quad$ Vertical & $2.42(0.97)$ & $3.40(1.85)$ \\
Peak frequency $(1-6 \mathrm{~Hz}): \dagger$ & $8.42(1.02$ & $2.59(1.38)$ \\
$\quad$ Horizontal & $9.02(1.50)$ & $8.54(1.04)$ \\
$\quad$ Vertical & $8.95(1.56)$ \\
$\quad$ Hork frequency $(7-12 \mathrm{~Hz}): \dagger$ & &
\end{tabular}

*Power is a measure of amplitude means (SDs) expressed as power units of log transformed measurements $\left(\mathrm{m} / \mathrm{s}^{2}\right)$.

†Means (SDs) are expressed in $\mathrm{Hz}$.

Table 5 Log power values and peak frequencies for leg tremor for minute two

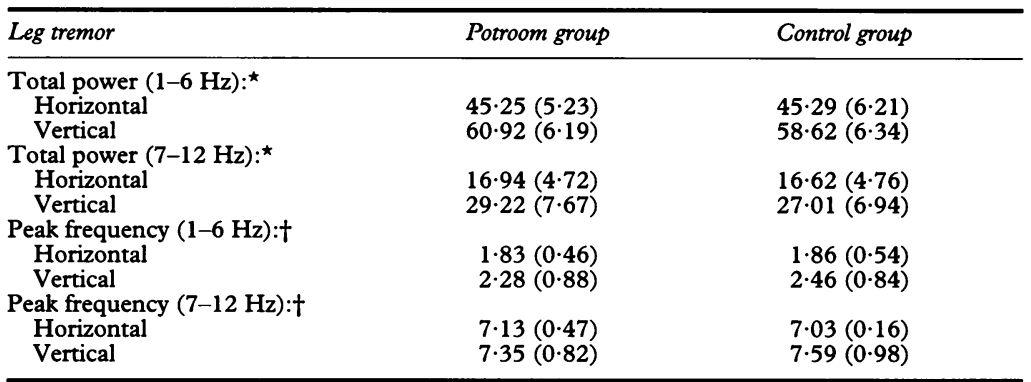

$\star$ Power is a measure of amplitude with means (SDs) expressed as power units of log transformed measurements $\left(\mathrm{m} / \mathrm{s}^{2}\right)$

tMeans (SDs) are expressed in $\mathrm{Hz}$

Table 6 Mean radius scores for the postural stability test (mean (SD))

\begin{tabular}{lll}
\hline $\begin{array}{l}\text { Mean radius score } \\
\text { (in) }\end{array}$ & $\begin{array}{l}\text { Potroom group } \\
(n=61)\end{array}$ & $\begin{array}{l}\text { Control group } \\
(n=37)\end{array}$ \\
\hline Eyes open on hard surface & $0 \cdot 22(0 \cdot 08)$ & $0 \cdot 21(0 \cdot 06)$ \\
Eyes open on soft surface & $0 \cdot 27(0 \cdot 10)$ & $0 \cdot 24(0 \cdot 07)$ \\
Eyes closed on hard surface & $0 \cdot 30(0 \cdot 14)$ & $0 \cdot 28(0 \cdot 07)$ \\
Eyes closed on soft surface & $0 \cdot 39(0 \cdot 13)$ & $0 \cdot 39(0 \cdot 14)$ \\
Standing on right leg & $0 \cdot 43(0 \cdot 15)$ & $0 \cdot 38(0.08)$ \\
Standing on left leg & $0 \cdot 38(0 \cdot 08)$ & $0 \cdot 37(0.07)$ \\
\hline
\end{tabular}

$\star_{n}=43$ For the potroom group and $n=26$ for the control group for left and right leg tests.

Repeating the analysis with former and compensation workers excluded made no difference to these findings.

The purpose of the $\chi^{2}$ analysis was to find whether there were more extreme scores indicative of clinical tremor in the potroom group. Total power measurements of tremor in both the visible and non-visible range in the second minute were arranged into deciles and the two study groups compared with the same tremor power variables (table 4). No significant results were found. When this same analysis was performed for power at peak frequency in the visible and non-visible range, a significantly higher $(P=0.02)$ result was found for the potroom group only in the nonvisible range in the vertical direction. All other results were normal and this isolated finding was not considered clinically relevant.

The statistical analyses performed to evaluate group differences for leg tremor were the same as the first analysis already described for the hand or arm tremor device. This was an analysis of group differences with repeated measures ANOVA for both power (amplitude) and frequency. This analysis was confined to the measurements from the second minute to control for the effect of fatigue which was found to cause increased tremor in the third minute. Table 5 shows the results for leg tremor, which indicate similar results between the two groups on all power (amplitude) and frequency measures. As found for arm tremor, the leg tremor measurements showed sensitivity to fatigue effects, but there were no differences between the exposure groups. Age adjustment made no difference to the results for arm or leg tremor.

\section{POSTURAL STABILITY}

The length and mean radius of the postural sway path are clinically relevant variables measured by the postural stability test. ${ }^{17}$ No significant differences between the potroom and control groups were found for these two variables for any of the test conditions. Table 6 shows the results for each group for the mean radius, measured in inches, for the 12 test conditions. Further analysis was undertaken to look for interactions between different test variables, with the raw data and ratios of the raw scores. Although there were a few isolated significant findings, mainly for the mean radius, there was insufficient concurrence among the variables length of path, area, and mean radius to suggest any neurologically meaningful differences between the two groups.

\section{REACTION TIME AND VOCABULARY TESTING}

The mean (SD) reaction times were computed for each participant across all trials. Also, the fastest and slowest reaction times were recorded for each. Two participants, whose fastest reaction times were $<100 \mathrm{~ms}$, were probably not following instructions and were omitted from the analyses. Also, one participant could not complete the reaction time test due to disability and another due to equipment failure.

The mean (SD) reaction time for the 59 potroom workers was $279 \cdot 1(55.93) \mathrm{ms}$, and for the 37 controls it was $261.8(45.22) \mathrm{ms}$; these were not significantly different $(F(1,94)$ $=2.06, P=0.155)$. The means of the two groups are similar to those obtained in a previous NIOSH study of 932 subjects who had reaction time evaluated with the neurobehavioural core test battery reaction time test. ${ }^{20}$

Scores were obtained for each participant on the vocabulary portion of the WAIS-Ra. ${ }^{19}$ Four workers (one from the potroom group and three from the control group) were excluded from all analyses of vocabulary scores because they reported that their primary language was Spanish. The mean vocabulary score for the 62 potroom workers was 44.8 , and the mean score for the 34 control workers was $41 \cdot 5$. The difference between the means of the two groups was not significant ( $F$ $(1,94)=1 \cdot 82, P=0 \cdot 181)$.

For all neurological tests, no significant changes in the findings occurred when the analyses were repeated with former and compensation workers excluded. 


\section{Discussion}

The prevalences of neurological symptoms were consistently higher in the potroom group, although a significant difference between the potroom and control groups was found only for three symptoms. However, the $95 \%$ CIs of the ORs were wide for most symptoms due to the small numbers of participants reporting symptoms. Finding higher reporting rates of neurological symptoms in the potroom group is consistent with previous publications. ${ }^{78}$ The demographic characteristics (age, education, and race) of the two groups were similar. Therefore, any differences in symptoms between the two groups are not likely to be due to confounding by these factors. This was confirmed for age as there was no difference in the results after adjustment for age.

Because of the large amount of previous publicity within the plant about the possibility of neurological problems among potroom workers, and the fact that the two published case series comprised workers from this plant, ${ }^{23}$ the possibility of an information bias operating among the potroom workers cannot be discounted. An information bias is said to be operating when members of one of the groups under study (usually the exposed group), because of previous knowledge about the health outcome and exposure being investigated, are more likely to report symptoms because they can anticipate the correct answers. This bias only operates in the case of the collection of subjective data, such as the reporting of neurological symptoms.

As it had been anticipated that an information bias may be operating among workers at the plant, the study incorporated several objective measures of both motor and cognitive function. Objective indicators of neurological impairment are an important part of any study investigating neurological abnormalities in workers exposed to suspected neurotoxins. This is because they may be able to detect abnormalities in both the clinical and subclinical range and they can test consistency with subjective indicators of neurological disorders, such as symptom reporting. In this study, the results of the objective indicators of neurological impairment (clinical neurological examination, arm or leg tremor tests, and postural stability tests) did not show evidence of an association between potroom work and tremor or incoordination to support the symptom results.

The neurological examination found high rates of neurological abnormalities in both groups. However, most of the abnormalities were minor, did not relate to the prime neurological problems of interest in this study (tremor or incoordination), or had an apparent non-occupational cause (diabetes or familial). Although there was no difference between the two groups in clinical tremor found on neurological examination, this examination is only able to detect tremor in the visible range-that is, in the frequency range of $1-6 \mathrm{~Hz}$. Tremor abnormalities in the non-visible range, potentially an early indicator of neurological damage, ${ }^{15}$ is likely to be missed by medical examination alone.

Objective tremor testing of both hand or arm and leg found similar results for both the potroom and control groups. This was true for tremor in both the visible and non-visible range. Therefore, these findings did not support the finding of increased difficulty in buttoning which may be an indication of tremor in the potroom group, but supported the negative tremor findings on clinical examination. The tremor test was found to be sensitive to effects of fatigue, and this effect was controlled for by only analysing data collected in the second minute of testing.

There may be several reasons why these tremor results differ from those found in the only other published study which objectively assessed tremor. ${ }^{8}$ This Norwegian study involved a much smaller study group with a mean age nine years older than the group in the present study. Therefore, age related tremor effects may have been a factor in the Norwegian study. Secondly, a less sensitive method, the Klove-Matthews static steadiness test, was used to measure tremor. Thirdly, the Norwegian group worked in a Söderberg smelter which has a different pattern of potroom exposure than that experienced in a prebake smelter, as in the present study. This last point may not be so relevant for differences in aluminium exposures between the two types of smelter as it is usually only coal tar pitch volatiles, rather than the other potroom contaminants such as aluminium or carbon monoxide, which are higher in Söderberg smelters. ${ }^{21}$

The postural stability test was sensitive to the expected differences between eyes open and closed and the rigid and compliant standing surfaces. Although this test showed some isolated significant differences between the potroom and control groups for some interactions between test variables, there was insufficient concurrence among the variables of path length, area, and mean radius to suggest that these were neurologically meaningful differences. These inconsistent findings suggest that tests which identify the separate capacities of visual, proprioceptive, and vestibular functions should be used in future studies of postural stability in aluminium workers.

The mean reaction times were similar to values found in other populations, ${ }^{20}$ suggesting that simple visuomotor function was not impaired in either group. The lack of a difference in mean vocabulary score suggests that baseline levels of verbal intelligence were similar in both groups and therefore not an important factor in performance on other neurological tests. Examination of vocabulary scaled scores for each WAIS-Ra age group found that $96 \%$ of the workers were within one SD of the general population mean, indicating that vocabulary in both groups was within the reference range for the general population.

The members of each study group were selected on the basis of long term employment in the smelter, starting at a time when aluminium exposure in the potroom was higher than it is today due to the absence of hoods on the pots before 1972 . As neurological impairment due to chemical exposure is usually slowly progressive, the inclusion of groups of workers with at least 23 years since first exposure (all workers in the study started work at 
the plant before 1 January 1970) should have ensured that an appropriate latent period was built into the study design. The entrance criteria for each group were chosen to maximise the chances of finding evidence of neurological abnormalities, if present, in the subgroup most heavily exposed to aluminium in the plant, taking into account the available air monitoring data, likely differences in aluminium exposure, and years of work in the plant. However, these exposure estimates were very crude and exposure misclassification could have been a factor in the finding of no difference between the groups on objective neurological tests. Also, potroom workers may be exposed to several other airborne contaminants, such as carbon monoxide, which could be neurotoxic. Insufficient occupational hygiene data were available for such contaminants to measure these exposures.

One other possible explanation for the negative findings in this study is low power, as the number of study subjects was small. The study groups could not have been made larger, apart from having a higher response rate, without making the inclusion criteria less stringent, which would have lessened the difference in exposure between the two groups. For most of the reported symptoms, prevalence was higher for the potroom group, but this increase was significant for only three symptoms. Power calculations have shown that there was low power in the study, often less than $50 \%$ to show a significant twofold increase in reporting of these symptoms. The results for the objective tests of neurological function were very similar for the two groups across the range of tests used. Apart from showing no significant differences between the two groups, the differences in the results for the groups were not at levels which would be considered clinically significant. Therefore, although low power may have been an important factor in negative findings related to symptom reporting, it is unlikely that the negative findings on the objective tests can be fully explained on the basis of low power in the study.

One of the objectives in the design of this cross sectional study was to include former workers to reduce the effect of a survivor bias on the results. A survivor bias occurs when workers who develop the disease being investigated are more likely to have left the workplace than those workers not affected. This bias tends to underestimate the true relation between workplace risk factors and the disease being studied, because the workers who are in better health tend to remain in the workforce. Despite multiple attempts to identify and contact eligible former workers in each group in this study, participation rates were very low, especially for the former non-potroom workers. Therefore, there is a possibility that a response bias and possible survivor bias may play a part in the finding of no differences in the reported prevalences of abnormalities on neurological tests in the studied groups, although when former workers were excluded from the analysis, no significant differences in the findings were found. Survivor bias may be an explanation for the negative results in this study compared with the abnormal findings of the only other study in the aluminium industry of objective indicators of neurological function. ${ }^{8}$

Although the subjective findings relating to symptoms were not supported by the results of the clinical and objective tests for tremor and incoordination, symptoms without physical findings may be indicators of early subtle neurological disturbance. Because of limitations in the study design and the presence of several potential biases, a prospective study of long term aluminium exposure in potroom workers in a different aluminium smelter is probably required to find more definitively whether potroom work increases the risk of neurological disorders.

We gratefully acknowledge the assistance of Jenise Brassell, David Chrislip, BJ Hausler, Faye Bresler, Julie Robinson, Bobby Taylor, and Stephen Brightwell who provided field assistance and technical support. MS was funded by a fellowship from the Australian National Health and Medical Research Council to undertake this work as a visiting research Research Council to
fellow at NIOSH.

1 McLaughlin AIG, Kazantsis G, King E, Teare D, Porter RJ, Owen R. Pulmonary fibrosis and encephalopathy associated with the inhalation of aluminium dust. $B r \mathcal{f}$ Ind Med 1962; 19:253-63.

2 Longstreth WT Jr, Rosenstock L, Heyer NJ. Potroom palsy? Neurologic disorder in three aluminum smelter workers. Arch Intern Med 1985;145:1972-5.

3 White DM, Longstreth WT Jr, Rosenstock L, Claypoole KHJ, Brodkin CA, Townes BD. Neurologic syndrome in 25 workers from an aluminum smelting plant. Arch Intern Med 1992;152:1443-8.

4 Langauer-Lewowicka $H$, Braszczynska $Z$. A trial evaluation of combined action of certain physical and chemical and harmful factors on the central nervous system. Neurol Neurochir Pol 1983;24:91-6.

5 Rifat SL, Eastwood MR, Crapper D, McLachlan DR, Corey PN. Effect of exposure of miners to aluminium powder. Lancet 1990;336:1162-5.

6 Hosovski E, Mastelica Z, Sunderic D, Raduvolic D. Mental abilities of workers exposed to aluminum. Med Lav 1990; 81:119-23.

7 Sjogren B, Gustavsson P, Hogstedt C. Neuropsychiatric symptoms among welders exposed to neurotoxic metals. $B r \mathcal{F}$ Ind Med 1990;47:704-7.

8 Bast-Pettersen R, Drables PA, Goffeng LO, Thomassen Y. Neuropsychological deficit among elderly workers in aluminum production. Am f Ind Med 1994;25:649-62.

9 Altmann P, Hamon C, Blair J, Dhanesha U, Cunningham J, Marsh F. Disturbance of cerebral function by aluminium in haemodialysis patients without overt aluminium toxicity. Lancet 1989;334:7-12.

10 Crapper DR. Aluminum and Alzheimer's disease. Neurobiol Ageing 1986;7:525-35.

11 Sjogren B, Lidums V, Hakansson M, Hedstrom L. Exposure and urinary excretion of aluminium during welding. Scand $\mathcal{F}$ Work Environ Health 1985;11:39-43.

12 Sjogren B, Elinder C, Lidums V, Chang G. Uptake and urinary excretion of aluminum among welders. Int Arch Occup Environ Health 1988;60:77-9.

13 Elinder CG, Ahrengart L, Lidums V, Pettersson E, Sjogren B. Evidence of aluminum accumulation in aluminium welders. Br F Ind Med 1991;48:735-8.

14 Larsen LB, Rivera RO, Wagner WL, Wisner BT. Report of industrial hygiene surveys conducted during fiscal year 1973 in six aluminum plants located in the northwestern United States. Sincinnati: National Institute for Occupational Safety and Health. 1973 .

15 Galinsky TL, Rosa RR, Wheeler DD. Assessing muscular fatigue with a portable tremor measurement system suitable for field use. Behavioural Research Methods of the Institute of Computing 1990;22:507-16.

16 Kondraske G. A noncontacting human tremor sensor and measurement system. IEEE Transactions of Instrumental Measurements 1986;35:201-6.

17 Dick RB, Bhattacharya A, Shukla R. Use of a computerized postural sway measurement system for neurobehavioral toxicology. Neurotoxicol Teratol 1990;12:1-6.

18 World Health Organization. Operational guide for the WHO neurobehavioural core test battery. Geneva: WHO Office of robehavioural core test battery

19 Wechsler, D. Wechsler adult intelligence scale-revised. New York: Psychological Corporation, 1981.

20 Anger WK, Cassitto MG, Liang Y, Amador R, Hooisma J, Chrislip D, et al. Comparison of performance from three continents on the WHO-recommended neurobehavioral core test battery. Environ Res 1993;62:125-47.

21 Ronneberg A. Mortality and cancer morbidity in workers from an aluminium smelter with prebaked carbon anodes-part I: exposure assessment. Occup Environ Med 1995;52:242-9. 